\title{
Esteban Echeverría y la liquidación del contrato social
}

Esteban Echeverría and the Liquidation the Social Contract

Esteban Echeverría e a liquidação do contrato social

\section{Justin Read}

STATE UNIVERSITY OF NEW YORK, BUFFALO, ESTADOS UNIDOS

Profesor Asociado del Department of Romance Languages \& Literatures de State University of New York, Buffalo. PhD. Comparative Literature, University of Michigan. Autor de Modern Poetics and Hemispheric American Cultural Studies (Nueva York: Palgrave Macmillan, 2009). Ha publicado numerosos artículos en varias revistas especializadas de América Latina, Estados Unidos y Europa. Correo electrónico:jread2@buffalo.edu

\section{Artículo de reflexión}

Documento accesible en línea desde la siguiente dirección: http://revistas.javeriana.edu.co doi: 10.11144/Javeriana.cl20-39.eelc 


\section{Resumen}

La crítica política revolucionaria de Esteban Echeverría indudablemente se basa en el ideal liberal de sujetos racionales y cultos, quienes libremente eligen establecer lazos fraternales entre sí para formar un pueblo unitario y nacional. Sin embargo, este ideal nunca se materializa en los espacios de los mundos que Echeverría habita (sean estos reales o ficticios). En lugar de solamente historizar al autor, el presente ensayo lee su obra desde el punto de vista geográfico del espacio y el lugar. Esta perspectiva revela un cuerpo de escrituras que, a pesar de centrarse en el sujeto liberal, ofrece un catálogo de diversas formas de la no-subjetividad. A contrapelo de las intenciones del autor, su obra inconscientemente permite la entrada a la capital de toda una inundación de fuerzas, tanto humanas como no humanas, en un momento clave en la formación del orden jurídico constitucional en la Argentina.

Palabras claves: liberalismo; teoría política; soberanía; subjetividad; espacio/lugar; ecocrítica

\section{Abstract}

The revolutionary political critic of Esteban Echevarría is doubtlessly based on the liberal ideal of rational and educated subjects, who freely choose to form brotherly ties among themselves to form a single nation. However, this ideal is never materialized in the spaces of the worlds Echevarría inhabits (real or fictional). Instead of merely historicizing the author, this essay reads his works from a geographical point of view of space and place. This perspective reveals a corpus of writing that, despite not being centered in the liberal subject, it offers a diverse catalog of forms of non-subjectivity. Going against the intentions of the author, his works unwillingly allow the entrance to the capital of a flood of forces, both human and non-human, in a key moment of the formation of the legal constitutional order in Argentina.

Keywords: liberalism; political theory; sovereignty; space/place; eco-critic

\section{Resumo}

A crítica política revolucionária de Esteban Echeverría sem dúvida baseia-se no ideal liberal de sujeitos racionais e cultos, quem livremente elegem estabelecer laços fraternais entre si para formar um povo unitário e nacional. No entanto, este ideal nunca é materializado nos espaços dos mundos que Echeverría habita (sejam eles reais ou fictícios). Em vez de apenas historizar o autor, o presente ensaio lê sua obra desde o ponto de vista geográfico do espaço e o lugar. Esta perspectiva desvenda um corpo de escritas que, embora centrados no sujeito liberal, oferece catálogo de formas várias da nãosubjetividade. A contrapelo das intenções do autor, sua obra inconscientemente permite a entrada à capital de toda uma inundação de forças, tanto humanas quanto não humanas, em um momento chave na formação da ordem jurídica constitucional na Argentina.

Palavras-chave: liberalismo; teoria política; soberania; subjetividade; espaco/lugar; ecocrítica

RECIBIDO: 3 DE MAYO DE 2015. ACEPTADO: 16 DE JUNIO DE 2015. DISPONIBLE EN LÍNEA: 01 DE ENERO DE 2016

\section{Cómo citar este artículo:}

Read, Justin. "Esteban Echeverría y la liquidación del contrato social". Cuadernos de Literatura 20.39 (2016): 165-190. http://dx.doi.org/10.11144/Javeriana.cl20-39.eelc 
LA CONSTITUCión DE la ley necesariamente comprende dos aspectos: la letra de la ley y la aplicación de la letra a los cuerpos físicos. Por un lado, gnosis y, por otro, physis. Con respecto al primero, es menester imaginarse una nueva ley e inscribirla dentro del código legal vigente; en este sentido, escribir la ley es obligatoriamente oportuno. Los legisladores se imaginan una nueva ley porque reconocen algo que falta (no existe una ley para gobernar una circunstancia emergente, o el código legal no aborda una ya nombrada circunstancia correctamente y, por ende, requiere modificación). De cualquier manera, la falta de la ley siempre precede su inscripción, así que escribir una nueva siempre responde al código legal anterior. Aun la revolución actúa sobre el código legal ya inscrito... para abolirlo. La letra de la ley es siempre histórica, procede después de la circunstancia de su propia ceguera: lapsos de su propia letra o incoherencia inarticulada frente a eventos en el mundo. Hay que saber todo eso para tener ley.

Cualquier ley puede ser escrita - autor-izada - y, sin embargo, no necesariamente conlleva autor-idad hasta que no se involucra con los cuerpos en el espacio. Si bien la autoría de la ley es histórica, su autoridad es siempre geográfica. El gnosis legal (sabiduría, imaginación, autoría, "letradismo") es temporal. Pero la physis legal (aplicación, autoridad, territorialidad) es espacial. Leyes e historias se pueden escribir, pero no tienen sentido hasta que ocupan un terreno geográfico, hasta que regulan las relaciones entre los cuerpos en espacios políticos, entre el uno y un otro ${ }^{1}$.

El espaciamiento entre gnosis y physis es la causa principal de los conflictos jurídicos y políticos. En la nomenclatura "clásica", puede decirse que nomos (el ordenamiento jurídico) viene del gnosis (el conocimiento) para componer el orden temporal: ha de ocurrírsele a la mente la carencia de orden para inscribir la ley que ordena la situación. Sin embargo, el nomos no regla nada hasta que arregla los cuerpos físicos, componiendo el ordenamiento de cosas en el espacio. Para legalizar una ley, ha de pasar una especie de "trans-acción" entre el tiempo y el espacio durante el cual la ley cesa de ser estrictamente temporal-histórica, deja de ser solamente la letra de la ley, aunque todavía no se ha hecho espaciosituacional. Así, la ley se constituye en la aporía entre un orden temporal y un ordenamiento espacial; tal aporía ofrece la posibilidad de anomía (a-nomos) si la trans-acción del tiempo al espacio, de la historia hacia el mundo, no toma lugar propiamente. La ley no transmite fuerza hasta que el conocimiento entra en el

1 En el presente ensayo "cuerpo" se refiere de la misma manera a una entidad "subjetiva" $\mathrm{u}$ "objetiva", "humana" o "no humana". La regulación jurídica de los cuerpos, entonces, cubriría las relaciones entre sujeto-sujeto, sujeto-objeto u objeto-objeto. 
mundo, hasta que el sujeto se traslada sobre o en el objeto; y en el mero instante de tal transacción, la ley se puede negar a sí misma, entrar en un estado acrático, lo que Giorgio Agamben ha llamado (al estilo de Heidegger) la "fuerza de la tey" (Agamben). Esta laguna acrática también se puede ubicar como el sitio de la literatura - un tipo de imaginación autoral no autorizado como conocimiento per se, y que sirve de lugar o situación sin una orientación física fija.

Sostener tal definición de la literatura como regla general no es el objetivo del presente ensayo, sino la manera en que una obra literaria en particular se sitúa precisamente en la aporía entre el conocimiento, la naturaleza y la ley. De hecho, pareciera que El Matadero de Esteban Echeverría ${ }^{2}$ no intenta nada menos que explotar esta aporía para fines revolucionarios. Una lectura "común" mantendría que Echeverría busca "liquidar" el orden político vigente a favor de otro más a su gusto. El relato señala el fin de la tiranía dictatorial bajo el reino federalista de Juan Manuel de Rosas y proclama el inicio del estado unitario-liberal. A primera vista parece criticar la circunstancia histórica en el presente del autor para abogar por un futuro basado en los ideales que este consagró en su documento político fundamental, el Dogma Socialista. Este tipo de lectura se centraría en el idealismo romántico que sin duda forma el centro filosófico de su biografía. Es decir, El Matadero condena el orden jurídico-político de su tiempo, visto como ilegítimo por su dependencia en el uso de la fuerza y la violencia, a favor de un contrato social basado en la fraternidad de sujetos soberanos, quienes libremente eligen ceder su poder al estado para representar su libertad individual "contractualmente" $y$ "constitucionalmente" en la forma social del estado-nación.

Evidencias contextuales mostrarán que esta lectura no es enteramente correcta. Sin embargo, el propósito del presente ensayo no es llevar a cabo un revisionismo histórico, en el sentido de recuperar las intenciones autorales del archivo; más bien, nuestra intención es dar una lectura a contrapelo de las intenciones e ideales del relato en sí, en contra de su propia orientación política con respecto a la constitucionalidad de la ley. En juego en esta presentación de la historia de Echeverría hay ciertas transacciones - entre cultura y naturaleza, lo humano y no-humano, el tiempo y el espacio, la historia y el lugar, el "dentro" y el "afuera" - por las cuales el poder del estado procura su legitimidad. La lectura "directa" del relato mantendría que la legalidad legítima se resuelve en la subjetividad de un sujeto-ciudadano argentino capacitado con razón y juicio (gnosis).

2 Echeverría, Esteban. Obras escogidas. Eds. Carlos Altamirano y Beatriz Sarlo. Caracas: Biblioteca Ayacucho, 1991. Todas las citas de textos primarios de Echeverría son extraídas de este volumen. 
Pero, se puede leer a la "inversa" también, cuando se considera el aspecto "anverso" de la legalidad, su incorporación en el mundo físico.

\section{El Sujeto Real}

De una u otra manera tenemos que aceptar que una inundación no exhibe gnosis en ningún sentido. ${ }_{\mathrm{C}}$ Es entonces pura y exclusivamente física? Una inundación no es capaz de emitir un juicio racional, así que sería natural asumir que no tiene acceso a la ley positiva, al estar enteramente gobernada por la ley natural. Los diluvios son excluidos de la vida política. Y, sin embargo, en el siglo XXI, en una era de cambio climático global causado por la política económica del capitalismo industrial, las inundaciones se han convertido en un problema político de suma importancia (Aceh, Nueva Orleans, Nueva York...). El calentamiento de la atmósfera amplifica tormentas cada vez más fuertes que someten a las poblaciones litorales a inundaciones intensificadas y, por eso, se emiten respuestas políticas a la crisis. ¿Cómo es que son solamente gobernadas por la "ley natural" si, de hecho, son creadas en parte por la sociedad: es decir, por el fallo de la "ley positiva" para regular la liberación de desechos carbónicos al ecosistema? Aunque no son entes políticos propiamente dichos, las inundaciones parecieran exhibir cierta especie de agencia histórica, pues la historia se estrella sobre cuerpos, ciudades, sociedades, culturas.

En otras palabras, una inundación carece de subjetividad soberana, pero este hecho no excluye su poder natural sobre la historia social. Como si fuera su espejismo simétrico, actúa en el mundo físico, aunque le falte una corporalidad; la soberanía es pura sociabilidad, pero no está excluida del mundo natural. Puede definirse como el exceso erótico expuesto espectacularmente para asombrar al súbdito (Bataille) o como la autoridad de decidir los límites legales de la ley en sí (Schmitt). En estos casos, la teoría política definiría la soberanía en términos espirituales: la licencia dada por Dios, el comportamiento licencioso permitido por esta licencia sagrada, o la secularización de la licencia sagrada para autojustificar el poder real. Si el soberano es agente de la historia, la inundación es agente de la realidad, un ente puramente físico. Cualquier agencia histórica que se exponga por su naturaleza tendría que ser "reaccionaria": no promueve la historia, sino que fuerza reacciones históricas. La inundación es algo que sucede, a lo cual los actores políticos están forzados a reaccionar. Teóricamente se impone una posición política sobre la inundación, así sea siempre reaccionaria (y jamás revolucionaria), y no se indague en el vínculo preciso entre la inundación y su agencia histórico-política en potencia.

El Matadero radicalmente ha aludido hasta hoy una caracterización de su concepción de la fuerza. Su trama reside entre la fuerza física absoluta de la inundación 
y la espiritualidad absoluta de la soberanía. Es una historia que se escapa de una historización fácil. El relato abre declarando que los eventos contados ocurrieron verdaderamente, empezando con la inundación de Buenos Aires: "Diré solamente que los sucesos de mi narración, pasaban por los años de Cristo de 183..." (123). El narrador elige no darnos la fecha exacta de su historia, aunque especifica un tiempo y un espacio: "Estábamos, a más, en cuaresma, época en que escasea la carne en Buenos Aires..." (123). Además, la procedencia de la historia en sí es tan exacta como vaga. Echeverría escribió el relato entre 1838 y 1840, pero no lo publicó formalmente - se escondió de la vista pública o circuló como un tipo de samizdat avant-la-lettre. El relato no vio la luz hasta 1871, después de la muerte del autor (el Echeverría histórico) y el exilio del soberano (Rosas, a Southampton, Inglaterra) tan salvajemente criticado por él. La naturaleza de El Matadero está en desorden -its time is out of joint.

La temporalidad de la historia necesariamente demanda una atención cuidadosa, dado que la narración se dirige a un evento (o quizás "Evento", en la terminología de Alain Badiou) que suspende la ley y re-orienta la historia. Asumimos que la trama es bien conocida para el lector, dado que el relato es de los más canónicos de la literatura latinoamericana. Pero como recordatorio, más o menos empieza con una inundación en la capital, seguida por una hambruna general, la ausencia de preparación por parte de las autoridades y la carencia de carne a causa de la estación cuaresmal; se dan recriminaciones de parte de los clérigos católicos en apoyo al dictador Rosas y en contra de la oposición unitaria cuyos pecados desataron la ira de Dios y la llegada de días apocalípticos en Argentina; se desencadena un brote de indigestión causado por la falta de carne y una insurgencia de flatulencias que el dictador confunde con una revolución; la suspensión de la Cuaresma para permitir la entrada de cincuenta novillos al Matadero de la Convalecencia; la matanza de estos seguida por una lluvia de vísceras sobre los cuerpos de negras y mulatas; la emergencia inesperada de un toro entre los novillos que embravece en el corral; la decapitación de un niño cuando los matadores tratan de someter al toro; la escapada del animal por las calles de Buenos Aires, perseguido por una muchedumbre hambrienta que procede a pisotear a un inglés en el barro; la matanza del toro y el ofrecimiento casi sacrificial de sus testículos; la captura, tortura y posible intento de violación a un joven unitario que por casualidad cruzaba el área del Matadero; y termina finalmente con la misteriosa, espontánea y explosiva descomposición de dicho unitario. Pedimos disculpas por la extensión parca y un poco caótica de este resumen, pero la hemos hecho así a propósito. La progresión de la A a la $\mathrm{Z}$ en la narración sigue un orden temporal, pero no racional. Es precisamente la falta de un orden racional lo 
que hace al texto particularmente efectivo como farsa. La estructura narrativa en sí cuestiona la "oportunidad" temporal de la historia. ¿En qué sentido se puede decir que un evento natural-histórico como una inundación implica o exige el sacrificio político y socio-histórico al final de la historia? Los movimientos en el tiempo de la narración no son necesarios, no se pueden acertar lógicamente, así que no hay en verdad una lógica racional de causalidad que propicia el paso de un evento al otro.

El joven unitario que aparece al final de la historia proclama un sacrificio ritual basado en una lógica absurda: niega su propio ser para afirmar el ser subjetivo-liberal. Se incorpora a la subjetividad racional al mantener su anonimato y al faltarle la astucia necesaria para escapar de su destino. El unitario es subjetividad per se sin nombre propio. Así, la escena de su muerte está envuelta en una paradoja y, por esta razón (quizás), se presta alegóricamente a la subjetivación lacaniana. Martín Sorbille ha sostenido que en El Matadero esencialmente se alegoriza un encuentro subjetivo con el Real lacaniano (Sorbille). Para Sorbille, Rosas es una figura fantasmal que reina sobre el mundo diegético del relato como la (des)encarnación de lo Real (eso que causa y, sin embargo, desafía el orden Imaginario y Simbólico en el pensamiento de Lacan); Rosas también funciona como objet petit a en la formación subjetiva del unitario; y sirve de Significante Maestro y super-yo. Es decir, se menciona al dictador bajo el título de "Restaurador de las Leyes", pero apenas aparece. Como supuesto Restaurador, Rosas estructura los eventos de la historia. Sorbille correctamente caracteriza el texto como una serie de sacrificios exponencialmente más violentos por parte del dictador: la inundación es proclamada como un presagio de retribución divina y apocalíptica, para que se sacrifiquen primero los estómagos (metafóricamente) y seguidamente los novillos (literalmente); luego las mujeres negras y mulatas, un niño y, entonces, el arisco toro. La multitud cautivada ante estos sacrificios vuelca su sed de sangre sacrificial hacia el joven, quien aparece como si hubiera caído del cielo. La muchedumbre lo amenaza con cortarle la lengua y matarlo, y lo ata desnudo a una mesa en postura de crucifixión, quizás para sodomizarlo con una verga. Pero antes que se consuma la violación, el unitario inexplicablemente se desangra, crucificándose efectivamente a sí mismo.

Una por una, las víctimas aparecen repentinamente - un toro, un niño, un unitario- y son inmediatamente transformados en objetos sacrificiales para el goce del poder fálico (Rosas). Mientras menos aparece el Restaurador, según Sorbille, más se desincorpora el poder soberano, y más pareciera deificado ordenando orgias sangrientas en su honor. La aparición casual (y no causal) del unitario redobla así esta figuración de la soberanía como su espejismo simétrico. 
El joven habla como un sujeto soberano equipado con suficiente razón como para resistir el poder falocéntrico de Rosas; es decir, el propósito del unitario dentro de la lógica diegética de la narración es la resistencia frente al Falo. El unitario es obstinado: "Tengo de sobra voluntad y coraje para ti, infame" (137). Denuncia fuertemente la crueldad del federalismo: "Sí, la fuerza y la violencia bestial. Esas son vuestras armas, infames. El lobo, el tigre, la pantera, también son fuertes como vosotros. Deberíais andar como ellas, a cuatro patas" (137). Y, sin embargo, su misma voluntad subjetiva, diferenciada aquí de los "animales" bestiales, obliga a que este acepte la "Ley" falocéntrica del Sujeto de todas maneras. Es decir, Sorbille sostiene que la Ley del Sujeto es redimida y restaurada dentro del cuerpo del joven en el momento en que este mismo se descompone hacia fuera. El Restaurador de las Leyes encuentra satisfacción en capturar el cuerpo del unitario; su resistencia a este mando, en turno, lleva un pánico psíquico (neurosis que se hace sicosis), hasta el momento en que acepta el poder soberano como límite de prohibición dentro de su cuerpo, sin necesitar los golpes explícitos del poder desde afuera con una verga totémica. Para el unitario, resistir el poder soberano de Rosas es aceptar la soberanía como límite para ser excedido. En este punto de suma resistencia y sumisión, la Ley (el "super-yo") no queda ni dentro ni fuera del cuerpo, sino adentro y afuera a la vez.

No es nuestra intención cuestionar la lectura de Sorbille, un crítico que ha destapado la subconsciencia de Echeverría mejor que nadie. No obstante, su interpretación no nos permite especificar las dimensiones políticas, históricas y geográficas del relato. El valor de una aproximación lacaniana reside precisamente en su a-historicidad; la teoría pasa más allá de la historia para inferir cómo la historia del sujeto se origina - siempre anacrónicamente, afuera del tiempo. Pero el objetivo de El Matadero es criticar un paso falso en la historia política de la Argentina dentro del tiempo y apuntar hacia una nueva re-territorialización de la ciudadanía. En otras palabras, Sorbille figura a Rosas como una integración de conceptos lacanianos diferenciados (lo Real, objet petit a, el super-yo) bajo el signo del "Restaurador de las Leyes", pero su intención no es examinar cómo este signo "flotante" podría denominar situaciones jurídicas reales.

Las implicaciones políticas del pensamiento lacaniano han sido elaboradas por no-lacanianos strictu sensu. Desde la perspectiva de Badiou, por ejemplo, habría que leer el martirio del unitario de distinta manera. Su muerte sacrificial se elevaría al estatus de un Evento badiouniano: un suceso imprevisto que no puede ser imaginado, simbolizado o contenido bajo las leyes que gobiernan una situación dada. El Evento abruptamente descompone la situación (sus leyes, sus normas, su lugar) y, entonces, exige la emergencia de un nuevo Sujeto Histórico 
capaz de recomponer el nuevo orden mundial (stasis) retroactivamente. En fin, el Evento destruye el reino de lo mismo, para revivir un otro mismo bajo la mirada de un nuevo Sujeto.

Como Restaurador de la Leyes, Rosas había promulgado el anacronismo, dentro de la historia y no fuera de ella. Restauró el derecho divino de los reyes: la ordenación de la soberanía monárquica-absoluta bajo el patrocinio de Dios y el Papa; o, mejor dicho, la re-ordenación de una monarquía nulificada por las Guerras de Independencia. El soberano "restaurado" gobierna el presente de la Federación Argentina... pobremente. Al faltar una pretensión verdadera al poder, no logra controlar la situación completamente en la capital, así que requiere la aplicación constante de una violencia brutal. En este sentido, no puede personificar lo Real lacaniano, no solamente porque es un soberano esencialmente ficticio, sino porque aparece (y desaparece) dentro del mundo diegético - ficticio - de la narración literaria.

No obstante, uno podría localizar otra voz de lo Real, otro personaje que no es Rosas, verdadero y ficticio, y quien reside por dentro y por fuera del cronotopo de la historia. Esta voz sería nada menos que la de mismo Esteban Echeverría: una figura que era una realidad histórica y cuya voz dentro de su historia es la de un narrador ficticio elaborando una historia imaginada. No hay mejor explicación de la muerte del unitario que pensarla ordenada, con una precisión sorprendente, por el autor-cum-narrador para reclamar una transformación histórica. Dado que el narrador también es un unitario, debe reconocerse que no hay un único unitario dentro del relato - el unitario no es exactamente unitariosino que hay dos, quienes son imágenes simétricas, espejismos uno del otro. El primero es, desde luego, el desafortunado joven que infelizmente tropieza por el escenario del Matadero. Es un sujeto incompletamente formado, un sujetoque-no-sabe completamente la situación en que se ha metido. Al confrontar la oposición política directamente, se expone a sí mismo a la irracionalidad de las presunciones político-históricas federalistas. La confrontación también causa su desangramiento milagroso, una ocurrencia imprevista que no se puede explicar por la ciencia racional; de este modo, destruye las leyes gobernando el "mismo" lugar en que tropieza. Este evento, sin embargo, no podría erigirse al estatus de un Evento si no estuviera recompuesto a posteriori como el origen a priori de la revolución política. Tal recomposición solo la efectúa el narrador: el sujeto-quemira la historia nuevamente desde un futuro certero. En términos de Badiou, el narrador ("Esteban Echeverría") es el nuevo Sujeto Histórico, quien restablece mesiánicamente la "misma situación" (del Matadero, de Buenos Aires, de Argentina) como "otra" misma situación. El narrador relata la historia de cómo el Buenos Aires del pasado se transformó en el "mismo" Buenos Aires en el 
futuro de la historia, un Buenos Aires liberal-moderno en vez de un Buenos Aires monárquico-federalista.

Este psicoanálisis del narrador Echeverría como figuración de lo Real (el Sujeto que manda subjetividad) es confirmado por Slavoj Žižek, quien en esta situación me autoriza para hablar del asunto, pues ha realizado una breve discusión de El Matadero en su libro The Parallax View. Žižek analiza el relato como una fantasía política del orden burgués: la subjetivación lacaniana no es una alegoría anacrónica de alguna ley universal y a-histórica; trata, más bien, de los deseos de una clase histórica (diremos, una burguesía liberal-iluminada) que quiere asumir el poder a fuerza de su propia "iluminación" autodenominada, pero sin el desorden indelicado de una revolución verdadera que impediría su estilo de vida, pues, burgués. La auto-aniquilación del unitario claramente niega la posibilidad del falso soberano a infligir más violencia contra el cuerpo político liberal. Simultáneamente, este acto de jouissance extremo también previene a la muchedumbre lumpen de violentar el cuerpo unitario de una manera bruta y visceral. En este sentido, el unitario-que-sabe (el narrador) sueña con ascender sobre las normas gobernando la situación dictatorial, pero sin el esfuerzo de sangre, sudor y lágrimas que realmente se requiere para derrocar a Rosas y el federalismo. Como resultado, según Žižek, el final del relato en verdad representa una "revolución descafeinada" (309).

\section{El No-Sujeto}

Hasta este momento nuestra discusión ha presumido que el propósito de $E l$ Matadero es proponer un sujeto nacional nuevo y una nueva ciudadanía nacional bajo un código legal constitucional. Desde luego, esta suposición solo es correcta en la medida en que siempre fue la meta plenamente manifestada por Echeverría durante su vida, como expresó en sus escritos políticos desde su entrada al Salón Literario en 1837 hasta su muerte. El Dogma Socialista de la Asociación de Mayo, su principal manifiesto político originalmente publicado en 1837 , claramente define un sujeto patriótico e iluminado con pleno derecho a la libre asociación y a un pensamiento racional como el átomo de vida política requerido para el "progreso" en Argentina. Cualquier cita del Dogma sería suficiente para comprobarlo: "La inteligencia, la virtud, la capacidad, el mérito probado: - he aquí las únicas jerarquías de origen natural y divino... El problema de la igualdad social, está entrañado en este principio: 'A cada hombre según su capacidad, a cada hombre según sus obras" (Echeverría 226) ${ }^{3}$. La igualdad y el movimiento

3 El socialismo de Echeverría fue evidentemente pre-marxista, aunque uno puede ver raíces comunes en su cita aquí a Henri de Saint-Simon. 
social son aquí habilitados por la "inteligencia, la virtud, la capacidad, el mérito" subjetivo; es decir, las ideas y los ideales de un sujeto libre. Las reflexiones del autor dadas en otras ocasiones solamente solidifican el hecho de que Echeverría propuso un nuevo demos: una nueva asociación de sujetos libres organizada democráticamente. En su Ojeada retrospectiva de 1846 afirma:

Queríamos entonces como ahora la Democracia como tradición, como principio y como institución. La Democracia como tradición de Mayo, progreso continuo. La Democracia como principio: la fraternidad, la igualdad y la libertad. La Democracia como institución conservatriz del principio: el sufragio y la representación en el distrito municipal, en el departamento, en la provincia, en la república". (171, énfasis del original)

La idea de la democracia proviene de las ideas de sujetos libres en fraternidad. En su "Discurso de introducción a una serie de lecturas" de 1837, Echeverría explícitamente expresa tal concepto de subjetividad liberal en términos psicológicos. Después de citar El Contrato Social de Rousseau, propone una revolución de ideas: "Capacidad, ideas; y no ideas vagas, erróneas, incompletas, que producen la anarquía moral, mil veces más funesta que la física, sino ideas sistemadas, conocimiento pleno de la ciencia social, de su alta y delicada misión y de las necesidades morales de la sociedad, que incautamente puso en ellos su confianza" (151).

Esta esquematización de la democracia está evidentemente tomada del romanticismo francés, como es bien sabido. Beatriz Sarlo y Carlos Altamirano han destacado que la estancia del autor por cinco años en París, en los años treinta, fue clave en su formación intelectual, literaria y política, a pesar de que no dejó información detallada sobre qué hacía en la capital francesa. De todos modos, Echeverría no solamente se llevó ideas liberales-románticas corrientes cuando volvió a Sudamérica, sino que estableció una norma para los letrados de su época al considerar, como un deber patriótico, hacer un viaje a París:

En los letrados recae, por otra parte, la responsabilidad de ser originales y la poesía, especialmente, deberá hacerse cargo de abrir el camino en una sociedad que es nueva, pero que carga con una herencia de la que es necesario separarse para que esa novedad (y fidelidad a lo "real") se realice por completo. Una literatura nacional (de ella está seguro Echeverría) es tan indispensable como las ciencias, la religión y las instituciones en la formación de la comunidad. Sobre los letrados cae la doble tarea de ser originales, rompiendo con el pasado colonial hispánico, y producir a partir de las ideas leídas en los libros franceses y las traducciones francesas de libros alemanes, una nueva cultura. (Altamirano y Sarlo, xv) 
Estas nociones no son nuevas para cualquier latinoamericanista de los últimos dos siglos. Nuestra intención al mencionarlas es solamente hacer una observación bastante sencilla: Echeverría indudablemente centró su filosofía política en la subjetividad liberal-racional concebida por el romanticismo europeo; pero también reconoció que esta subjetividad todavía no existía en los "desiertos" de su país natal. Una civilización "nueva" ocupada con un "hombre nuevo" todavía no había emergido en América. Por consiguiente, aunque el texto parece proponer cierto tipo de subjetividad liberal para habitar el país, en ninguna instancia es el caso que este sujeto verdaderamente aparezca en el relato. De hecho, para el resto del presente ensayo, analizaremos El Matadero nada menos que como un registro de varios tipos de no-sujeto ${ }^{4}$.

Desde luego los federales que atacan al unitario son incapaces de formar un pensamiento racional, están atrapados en una mentalidad de muchedumbre que ha de saciar su celo sanguinario. Es decir, se forma una masa que apenas se aproxima al estatus de "sujeto". Pero este "apenas-sujeto" o "no-sujeto" solo se puede reconocer desde una consideración de los espacios en que emerge; de hecho, una consideración tal del espacio y el lugar del escenario revelará todo un catálogo de no-subjetividades. Es fuerte la tentación de pensar que la muchedumbre ha "regresado" a un Estado Natural en el sentido rousseauno, en el cual los instintos animales no se pueden controlar. Esta interpretación implica la aseveración de un espacio denominado "la Naturaleza" que puede en verdad no existir en el mundo imaginado por Echeverría.

Entre los letrados-élite del siglo XIX (y quizás del XX e incluso del XXI...) la Argentina era vista como un "desierto". Julio Ramos ha anotado esta tendencia en su lectura de Sarmiento: "Si la condición de viaje en Sarmiento es el desnivel, la distancia entre lo alto y lo bajo, el proyecto de su escritura es la disolución del desajuste: cubrir el vacío. Nivelación que presuponía, a su vez, la necesidad de poblar el desierto americano con las estructuras de la modernidad" (Ramos 20, énfasis adicional). Aquí notamos una equivalencia connotativa entre "desierto"y "vacío" - aunque no hay cómo implicar una equivalencia entre los dos conceptos y una "naturaleza". Con el lema famoso (e infame) de "Gobernar es poblar", Juan Bautista Alberdi no solamente señala que hay que poblar el campo argentino para gobernarlo; intenta decir que debe ser poblado con la gente correcta para formar un "pueblo", una cultura nacional capaz de sostener un estado moderno. Alberdi dice tanto en palabras explícitamente racistas en Bases y puntos de partida para la organización política de la República Argentina:

4 Vea Moreiras (2006) para la teorización amplia del no-sujeto. 


\begin{abstract}
Hoy mismo, bajo la independencia, el indígena no figura ni compone mundo en nuestra sociedad política y civil. Nosotros, los que nos llamamos americanos, no somos otra cosa que europeos nacidos en América. Cráneo, sangre, color, todo es de fuera. El indígena nos hace justicia; nos llama españoles hasta el día. No conozco persona distinguida de nuestra sociedad que lleve nombre pehuenche o araucano. (Alberdi 82; énfasis adicional)
\end{abstract}

Alberdi publicó su libro para promover la ratificación de la Constitución que acababa de dirigir y escribir. Dice, en términos absolutamente ciertos, que las comunidades indígenas no tienen lugar dentro del territorio, la nación o la sociedad argentinos. No son sujetos, ni objetos, para el poder nacional. A un nivel básico, ellos están "fuera de lugar" en Argentina: no tienen lugar ni "componen mundo".

Esta frase curiosa, "componer mundo", es a la vez un eufemismo metafórico y una proposición filosófica de importancia ontológica y fenomenológica. A lo largo de las Bases, se refiere a América como un "desierto". Al analizar "La cautiva", Fermín Rodríguez ha visto la misma tendencia en Echeverría. En este caso el desierto expresa más una dimensión estético-poética del concepto nación que una descripción topográfica de la tierra. Todo lo que hay en las llanuras vastas al oeste de Buenos Aires es visto en el poema como un vacío absoluto. Al principio no hay nada, literalmente, en las pampas; así que la perspectiva de la voz poética sobre el paisaje es "divina": "un lugar vacante", escribe Rodríguez, "de una mirada aérea sin sujeto" (Rodríguez 158). El poema entonces interrumpe el vacío para que el paisaje pueda hacerse una cosa:

Nadie mira nada, porque si alguien estuviera allí, dando testimonio del desierto, el hechizo especial se rompería. Negando el acontecimiento de esa mirada paradójica, testimonio de un vacío inalterable, el desierto destituye la primera persona del punto de vista, como si allí nunca hubiera pasado nada, como si nada estuviera pasando, más que el espacio como acontecimiento - una pura naturaleza, un trozo de duración pura [...] Llamamos sublime a un paisaje sin testigo, sin otro, de cuya superficie se borra todo rastro de acontecimiento histórico, toda realidad humana. Nada ha pasado, porque no hay nadie allí para dar cuenta de ello: solo un dispositivo de representación visual o literaria, generador de una mirada [...] El desierto se abre como objeto solo para la mirada estética del genio, más amplia que el saber conceptual -el único tipo de subjetividad capaz de hacer ver un paisaje sublime y de interpretar "las armonías del viento" como un arpa romántica. (Rodríguez 158) 
El desierto en este caso no significa tabula rasa, porque jamás surge la mera posibilidad de ser cualquier tipo de tabla o página, en blanco o no. Es decir, en el discurso del criollo élite y liberal, el desierto denota un lugar totalmente desprovisto de objetos, porque no hay un sujeto para quien un objeto pudiera existir, para quien los objetos pudieran obtener un "ser". Ha de entenderse el "lugar" en este sentido como algo sublime, algo que precede el espacio, en contra de la denotación común de "lugar" como un espacio (ya existente) que se localiza a través de la memoria o el movimiento repetitivo. Rodríguez denomina este "pre-espacio sublime" como "pura naturaleza"; pero, la "pura naturaleza" no es la misma "Naturaleza" nombrada por los filósofos románticos, no es una conceptualización de una tierra salvaje más allá de los límites de la ciudad y la humanidad. Proponemos que el concepto desierto es nada más un marcador de lugar (place-holder) en el discurso liberal, para reservar el campo como un espacio por venir. El desierto, en este caso, es el "espacio-por-venir".

Hay gente que es indígena en este marcador de lugar, por supuesto, pero no cuenta como gente. Dado que el desierto es considerado un mero marcadorde-lugar en vez de un lugar propio, los indígenas no merecen derechos bajo la ley, porque la subjetividad en sí (protegida por la ley) es denegada de antemano dentro del vacío. De la misma manera, los indígenas ni siquiera pueden tener el estatus de objetos, porque sin posibilidad de "ser sujeto" en el desierto, definitivamente no se puede "ser objeto" (y viceversa). Los indígenas solamente aparecen en la cartografía conceptual del criollo para ser exterminados —una duración temporal sin lugar que, pues, infelizmente ya se ha acabado.

A diferencia de "La cautiva", El Matadero no intenta caracterizar a las sociedades indígenas ni al desierto en el cual se los van a matar. La situación de El Matadero es Buenos Aires, aunque tendremos que calificar cuidadosamente cuál Buenos Aires está siendo representado en el cuento. Como una localidad cívica, Buenos Aires debe ser un centro de la civilización. Mas la acción del relato no tiene lugar en el centro, sino en las márgenes de la capital. En la época, el Matadero del Alto se ubicaba al borde sureño de la ciudad, encima de una colina que lo protegía de las aguas crecientes del Riachuelo, dentro de una frontera liminal entre el núcleo urbano y la extensión rural de la pampa. En la cartografía imaginaria del letrado, esta zona intermediaria existía en "suspensión". Por un lado, estaba lo suficientemente apartada de la ciudad como para faltarle el civitas requerido para construir una civilización; y, por el otro, estaba lo suficientemente cercana al "desierto" como para sufrir la intrusión de la barbarie. Martín Kohan ha descrito esta "suspensión" en palabras muchísimo más elegantes que yo: 


\begin{abstract}
El Matadero señala la peligrosa cercanía de la violencia popular respecto del espacio de la ciudad. Esa violencia rústica de la barbarie federal, que más bien corresponde al ámbito rural, aquí se encuentra - sin perder del todo las marcas de aquel entorno - inquietantemente próxima de Buenos Aires, y pasa a funcionar como violencia suburbana. (Kohan 174, énfasis en el original)
\end{abstract}

En este sentido podemos decir que la muchedumbre federalista está tanto fuera del tiempo como fuera del lugar. Como entidad suburbana, no es capaz de progresar históricamente como una fraternidad de ciudadanos civilizados. Por ende, está inclinada a regresar a una condición bárbara de pre-historia, pre-lugar, "pura naturaleza", aunque esté íntimamente integrada a una crisis contemporánea. Mientras aumenta la violencia en el relato, desde explosiones de flatulencia hasta explosiones de sangre, se registra la mayoría de personajes dentro de la narración en términos de estados distintos de animalidad. Más directamente, el unitario denomina a la muchedumbre anónima como sub-humana: "El lobo, el tigre, la pantera, también son fuertes como vosotros. Deberíais andar como ellas, en cuatro patas" (137).

La única figura entre la muchedumbre que lleva un nombre propio en verdad es solamente un apodo, Matasiete: un carnicero, "hombre de pocas palabras y mucha acción. Tratándose de violencia, de agilidad, de destreza en el hacha, el cuchillo o el caballo, no hablaba y obraba" (135). Al faltarle la palabra para hacer razón, Matasiete adquiere una animalidad casi mitológica dentro de la historia. Después de someter al bravo toro que había escapado, hunde su daga en la garganta de la bestia, y sus brazos parecen desaparecer en las entrañas del animal hasta que su tronco está cubierto de sangre. Se le regala el matambre a Matasiete, pero no hasta que "libera" los testículos del animal para la consunción de la muchedumbre, bajo la aprobación tácita del "Juez" del Matadero (quien debiera prohibirla). En este punto, la atención de Matasiete se vuelve al unitario, a quien casi mata con la misma daga. El retrato último de Matasiete no es solamente la de un animal feroz, sino la de un hombre-bestia sangriento más bien parecido al Minotauro, con piernas humanas y su torso y cabeza ensangrentados, un tronco humano desaparecido en el cuerpo de un toro. Su propósito mítico dentro de la narración es transferir el poder bestial de los testículos a la muchedumbre, antes de procurar un sacrificio humano final.

Matasiete no es la única figura mitológica. Entre las cientos de personas en la multitud, el narrador toma nota de "negras y mulatas achuradoras, cuya fealdad trasuntaba las harpías de la fábula" (131). Como las mujeres-bestias del mito griego, estas harpías negras roban entrañas y causan estragos. Cuando una de ellas trata 
de fugarse con sebos y tripas, la muchedumbre (blanca) lanza una tormenta de sangre en su dirección, y así se inicia una pelea bizarra de "zoquetas de carne y bolas de estiércol" (132) que llueven por los cuerpos de todos los espectadores. Las "harpías" vuelven a aparecer después cuando un inglés "absorto en sus cálculos" es desmontado por la muchedumbre y tirado al barro a la orilla de la calle. En este momento adquiere el aspecto de "un demonio tostado por las llamas del infierno" (134) y, sin establecer una conexión interpersonal o lógica con ellas, las "negras achuradoras" reaparecen y "se zambulleron en la zanja llena de agua" (134) para escapar de la multitud enloquecida. El efecto es yuxtaponer y equiparar el nuevo aspecto "demoníaco" del inglés con la "magia negra" de las supuestas "harpías".

En fin: las masas del Matadero se caracterizan por modos distintos de bestialidad no-subjetiva. Son cuerpos humanos que se han "vuelto" bestias feroces; son hombres-bestias arquetípicos; o son mujeres-bestias malevolentes que condenan, por su mera apariencia, a todos en su alrededor a una negritud satánica. Dichas figuraciones no dejan espacio para que la muchedumbre (sea blanca o negra) tenga un futuro o un pasado: son figuras "eternas" y "sin tiempo" que solamente ocupan un presente extremo. Por eso son también figuras "sin espacio". Son cuerpos con una presencia animal fuera de su hábitat natural, todavía no incorporados al mundo de Buenos Aires. Por eso no son ni enteramente urbanas ni enteramente rurales. La muchedumbre suburbana ciertamente no es civilizada, pero tampoco completamente "natural". Son, en este sentido, no-sujetos (y noobjetos) atrapados dentro del marcador del lugar.

La consideración de Fermín Rodríguez con respecto a este place-holder (o "pura naturaleza") depende todavía de una mirada subjetiva para llamar el espacio del ser: "la mirada estética del genio, más amplia que el saber conceptual —el único tipo de subjetividad capaz de hacer ver un paisaje sublime y de interpretar" (Rodríguez 158). Como han notado numerosos críticos, Echeverría creía que Argentina solamente podría emerger como una nación verdadera si su política se originaba de una cultura nacional. El pueblo era el sujeto precisado para que el paisaje "sublime" se transformara en un lugar moderno, y no meramente un espacio-por-venir. Como se declara en la "Ojeada retrospectiva": "Todo para el pueblo, y por la razón del pueblo" (Echeverría 179). El dilema, como debe ser plenamente evidente ahora, es que el pueblo argentino, que por naturaleza pudiera servir de origen para la cultura nacional, todavía no tenía, en la (des)estimación de Echeverría, la facultad de la razón suficiente para ejercer la ciudadanía apropiadamente. El arte y la literatura servirían para cultivar a un pueblo en el porvenir; o, como Sarlo y Altamirano aclaran: "La paradoja exige que el arte nuevo refleje las costumbres y civilización argentinas y, al mismo tiempo, las funde" (xiv). En 
turno, la política de Echeverría se orienta a un futurismo insostenible, como Fabio Wasserman observa en relación con el Dogma:

Como se puede apreciar, no sólo propone constituir la futura nación, sino también los elementos de la nacionalidad, inexistentes pero necesarios según el principio de las nacionalidades sostenido por el romanticismo. Así, se entiende por qué la mayor parte de la calificaciones de argentino quedan reservadas para su generación o para entidades que se constituirían en el futuro: no encuentra en el presente elementos de la realidad dignos de ese nombre, mientras que los que encuentra en el pasado son los principios legados por la Revolución que no lograron encarnar social ni institucionalmente. (Wasserman 217-218)

La "ley de Echeverría", si se me permite la expresión, lee que Argentina es un lugar-por-venir en el momento que un sujeto-por-venir venga para transformar el desierto-sin-espacio en un terreno sobre el cual el pueblo-por-venir consolide una vigilancia soberana. Claramente, el Buenos Aires del cuento no es "pura naturaleza"; es decir, ya es un lugar con nombre propio, y eso plantea la pregunta de quién, exactamente, lo mira para darle el estatus de "lugar". ¿Qué tipo de "mirada genial" concretiza a Buenos Aires como un lugar? La respuesta inmediata es sencilla... e incorrecta: el unitario. Como ya hemos analizado, ha de considerarse al unitario como un aspecto parcial de una doble-subjetividad suspendida entre el presente y el futuro del universo diegético. El fallecimiento explosivo del unitario marca un evento, marca el presente; pero la acción de marcar es sacrificial en el sentido de que su inexplicabilidad solamente se resolverá en el futuro; la muerte del unitario interrumpe el orden de las cosas corrientes y señala un nuevo orden en el porvenir. Este orden-por-venir está encarnado en una imagen especular en forma de "Esteban Echeverría", una voz del porvenir y el único personaje capaz de juzgar a los actores de la historia moral, ética y políticamente.

Esta voz llama al Buenos Aires de El Matadero al ser, pero este hecho no indica que un sujeto liberal realmente exista en la historia. Kohan, con razón, arguye que el liberalismo no es solamente político en el relato, sino también económico, especialmente con respecto al "derecho a la ciudad":

Por cierto, entre los derechos que se reclaman ante la represión rosista, se cuenta el derecho a la libre circulación (junto con el derecho a hablar libremente y a respirar libremente) [...] Este reclamo en favor de la movilidad tiene también un aspecto económico, y el interés por la libre circulación se convierte en interés por la libre circulación mercantil. (176) 
El inglés "calculador" capta perfectamente este aspecto económico. Mientras que monta su caballo calculando los costos de exportación de su salero, la muchedumbre asusta a su caballo. No es solamente el caso que su derecho de transitar la ciudad es impedido en esta instancia, sino además su habilidad de efectuar contratos con sus socios en el negocio.

El derecho de circulación se re-presenta en forma del unitario, quien obviamente ha rechazado los negocios al ambular por la ciudad. Como una especie de flâneur porteño, el unitario ha optado por una vida de diversión en vez de una vida de trabajo. Asume que tiene el derecho de pasar por cualquier rincón de la ciudad a su gusto y, por supuesto, está terriblemente equivocado en este respecto: es apresado por la muchedumbre federalista y pierde su derecho a tener una vida libre (sea económica o no). Como hemos mencionado previamente, la muchedumbre no le quita la vida, solamente su derecho a ella, aunque él tampoco decida quitarse su propia vida. Si el sujeto soberano es definido por su habilidad para decidir sobre la excepción, como mantiene Schmitt (5), el unitario jamás decide sobre nada con respecto a las leyes biológicas que gobiernan su propio cuerpo. Simplemente explota. El unitario sugiere que su condición fue producida por su propia pasión, pasión inconcebible que no se puede intelectualizar. Cuando el Juez le pregunta por qué no viste la divisa en honor a Rosas y el luto en honor a la esposa difunta del dictador, contesta: "Porque lo llevo en el corazón por la Patria, ipor la Patria que vosotros habéis asesinado, infames!" (138). Implica entonces que él se reserva una naturaleza espiritual dentro de su cuerpo que no puede ser restringida por su razón, y ciertamente tampoco por una aplicación externa de la fuerza.

Al mismo tiempo, el unitario es identificado por su modo de vestir, en más de una manera. La muchedumbre lo reconoce como un unitario inmediatamente - sin pensarlo apenas - por su estilo. No solamente su falta de divisa y luto, sino su modo "europeo" de montar a caballo, sus ropas afrancesadas y, más que nada, sus barbillas en forma de U (inscribe su propio cuerpo con la letra del partido unitario). Echeverría explica en la "Ojeada retrospectiva" que estos modos eran mimetismos paródicos causados por el abandono. Los unitarios originales — quienes habían educado a la "nueva generación" en la política - abandonaron Argentina por Montevideo cuando los federales rosistas consolidaron su control sobre Buenos Aires:

La situación de esta generación nueva en medio de ambas facciones era singular. Los federales la miraban con desconfianza y ojeriza, porque la hallaban poco dispuesta a aceptar su librea de vasallaje, la veían ojear libros y vestir frac; traje unitario ridiculizado y proscripto oficialmente por su jefe en las bacanales inmundas con que solemnizó su elevación al mando supremo. Los corifeos del partido unitario, asilados en Montevideo, con lástima y menos- 
precio, porque la creían federalizada, o ocupada solamente de frivolidades. (Echeverría 164, énfasis del original)

En otras palabras, el ropaje del unitario en El Matadero es en verdad un disfraz utilizado para crear un espectáculo público de su desacuerdo político; su cuerpo muestra la semblanza de una subjetividad liberal en vez de necesariamente incorporarla. Esta semblanza proviene del abandono y la negligencia por ambos lados del espectro político: los rosistas victoriosos se burlan de su apariencia, mientras que los unitarios "originales" en el exilio lo han repudiado. Así era la situación ante la cual Echeverría (¿el autor? ¿ ¿el narrador?) tropezó cuando se juntó con el Salón Literario en 1837. En la época copiaba la imagen Stürm und Drang del poeta romántico melancólico cuando repentinamente se transformó en el líder intelectual del Salón. Casi una década más tarde cuando escribió la "Ojeada", Echeverría todavía estaba esperando la coalescencia de una oposición política, consigo mismo en el centro, aunque tal "partido nuevo" jamás se materializó durante su vida.

Aunque no entre en el mundo diegético de El Matadero como animal "devuelto" o "reducido", el espejismo-unitario muestra solamente las afectaciones de la subjetividad, es decir, una desafección. Exhibe los afectos exteriores de su afiliación con un movimiento político, pero en un momento en que los unitarios no estaban enteramente constituidos como sujetos políticos libres o soberanos. Por eso podemos llamarlos los "no-sujetos liberales". Y, al nombrarlos así, también podemos compararlos con otro registro de la no-subjetividad que podríamos llamar del "no-sujeto iliberal". Estos serían actores en la historia quienes mandaban en la ciudad, aunque no tenían el derecho moral o ético a la ciudad.

Hablamos aquí claramente de Juan Manuel de Rosas y su red de subtenientes en la capital. Si el soberano es, en la palabra inmortal de George W. Bush, el "decidador" - el que decide-, pareciera que el único actor en el relato habilitado de tomar una decisión es Rosas. Ha decidido que todos los argentinos tienen que vestir la divisa y luto en su honor. Decide permitir la entrada de los cincuenta novillos al Matadero como resultado de la inundación con que empieza el cuento. Pero, con respecto a esta última decisión —el acto soberano central del relato - el acto no es una consecuencia directa de la catástrofe natural. Rosas no permite que entren para superar una emergencia humanitaria entre sus súbditos; únicamente lo hace para contener una crisis política —una crisis, además, que risiblemente no existe. La inundación agrava una situación existente — digamos, una norma temporal de la cuaresma - en que falta carne en la capital, forzando a los sobrevivientes a comer proteínas alternativas que les causan flatulencia. El Restaurador de las Leyes percibe las ondas de flatulencia que explotan en la 
ciudad como un acto de guerra incitado por los unitarios, "creyendo aquellos tumultos de origen revolucionario" (128). Por eso Rosas suspende la prohibición cuaresmal de comer carne como gesto político para mitigar el disenso, y permite la entrada de los novillos al matadero.

Con esta acción, Rosas decide sobre el estado de excepción, no cabe duda. Mas esta decisión simplemente muestra la fraudulencia (y flatulencia) de su "soberanía". El estado de excepción se declara típicamente por el interés de preservar el orden constitucional de la ley (al suspender la Constitución). En esta instancia, esta forma de excepción no puede tener sentido porque en primer lugar no había constitución en Argentina (la Constitución nacional no fue ratificada hasta 1853 , bajo la dirección de Alberdi). Al permitir la entrada de los novillos a la capital, Rosas ha suspendido la ley eclesiástica de la prohibición cuaresmal de comer carne, una jurisdicción sobre la cual él no tiene derecho. Los clérigos se hacen cómplices tácitos de esta acción, pues desde el comienzo de la historia le han echado la culpa de la inundación a las transgresiones pecaminosas de la oposición liberal. En otras palabras, el clero católico ha cesado de servir como agentes de Roma para declarar su lealtad a un ídolo falso, un Redentor falso, el autodenominado "Restaurador de las Leyes".

La soberanía "imitada" de Rosas se transfiere a toda la jerarquía bajo su control, más notablemente en la figura del Juez del matadero. Descrito por el narrador como un "personaje importante, caudillo de los carniceros y que ejerce la suma del poder en aquella república por delegación de Restaurador" (130), el Juez funciona debidamente como representante legítimo del Estado o, mejor dicho, legitimado por el Estado federal. El Juez le impide a Matasiete ejecutar al unitario; pide su traslación a la "casilla" del Matadero, "un edificio tan ruin y pequeño" (130), donde arregla espontáneamente una farsa de juicio con todos los elementos de un proceso oficial. El Juez "formalmente" acusa al unitario por no llevar la divisa y guardar el luto. En su turno, al unitario se le ofrece técnicamente la oportunidad de defenderse, la cual toma oportunamente para insultar a sus captores bárbaros. Indignado, el Juez sentencia: manda que se le rasuren las barbillas, que se le quite su ropa y, por fin, que lo aten a una mesa para iniciar su crucifixión. El Juez "manda" esta sentencia, pero en realidad este supuesto "caudillo" del matadero no puede sino reaccionar a la demencia general de su muchedumbre. En vez de afirmar la soberanía del Estado de Rosas sobre los procedimientos del matadero, el Juez temporalmente aplaca la locura sanguinaria de sus "súbditos" antes de acceder a sus demandas de un sacrificio humano.

Como un no-soberano, el Juez no decide sobre nada. Y esta no-decisión es perfectamente lógica porque el Juez no es un juez. Es meramente un pobre con- 
tador de ganado: "En la casilla se hace la recaudación del impuesto de corrales, [y] se cobran la multas por violación de reglamentos" (130).

\section{Location! Location! Location!}

Digamos que el orden político-jurídico concebido por Echeverría es especulativo. La civilización argentina emergerá en un sujeto-por-venir llamado "pueblo". Si eso ocurre, pasará porque tal es la naturaleza del progreso, evidenciado en el progreso material de la civilización europea y norteamericana. Este orden de las cosas está directamente relacionado con el gnosis. Echeverría sabe que su país tendrá un futuro positivo porque es precisamente lo que ha pasado en el pasado. Su juicio en el asunto ha de ser abierto al escepticismo empírico, por supuesto, como fue teorizado un siglo antes por David Hume. Puede ser que el sol de la bandera nacional no suba mañana y que no se civilice la Argentina; pero la razón inductiva de Echeverría sugeriría lo contrario si se siguieran los pasos positivos esquematizados en el Dogma Socialista.

Aun si cabe duda en cuanto al futuro, la visión del mundo de Echeverría implica un orden alternativo de causa-y-efecto que es el orden operante dentro de El Matadero. Aunque sus tratados políticos propongan el cristianismo como moral rectora de la sociedad, asume que hay una causalidad natural en el universo que es comprobable por la ciencia. Esta lógica causal está mencionada explícitamente con respecto a la alimentación. Cuando desaparece la carne de la dieta, "Algunos médicos opinaron que si la carencia de carne continuaba, medio pueblo caería de síncope, por estar los estómagos acostumbrados a su corroborante jugo" (128). La mejor ciencia disponible predice que un cambio drástico en la dieta conllevará consecuencias serias para la salud pública, como por ejemplo la flatulencia masiva. No obstante, la causalidad médico-biológica se encuentra en conflicto directo con el orden eclesiástico: "y era de notar el contraste entre estos tristes pronósticos de la ciencia y los anatemas lanzados desde el púlpito por los reverendos padres contra toda clase de nutrición animal y la promiscuación en aquellos días destinados por la Iglesia al ayuno y la penitencia" (128). Ocurre una "guerra intestina" mientras la Iglesia intenta controlar la consciencia del pueblo a través del estómago. La guerra es una lucha entre dos nociones rivales de causa-y-efecto. Contra las leyes naturales descubiertas por la ciencia, las prohibiciones cuaresmales no pretenden ser naturales, aunque los sacerdotes ruegan su aceptación naturalizada. La prohibición se impone por voluntad divina. La gente ha de privarse de comida contra sus propias necesidades naturales, porque Dios juzga a la gente por sus pecados y la Ley de Dios exige sumisión. 
La transformación del orden causal aparece primero en la representación de la inundación. Para el narrador, simplemente resulta que la inundación inunda: "Sucedió, pues, en aquel tiempo, una lluvia muy copiosa" (124). Naturalmente, cuando son suficientemente copiosas las lluvias, ocurre una inundación; es propiedad natural de los líquidos, causa-efecto. Para la Iglesia, sin embargo, la inundación - ahora entendida como la reiteración del Diluvio- señala el fin del tiempo, un dictamen divino contra los unitarios: “¡Ay de vosotros, unitarios impíos que os mofáis de la Iglesia [...] Vuestra impiedad, vuestras herejías, vuestras blasfemias, vuestros crímenes horrendos, han traído sobre nuestra tierra las plagas del Señor. La justicia del Dios de la Federación os declarará malditos" (126). La futuridad de estas declaraciones pertenece a otro orden enteramente: la falta de piedad unitaria ha causado la inundación, para que los unitarios sean formalmente declarados malditos por Dios, para que Su juicio final llueva sobre Buenos Aires. No hay una lógica necesaria vinculando estos eventos en el futuro, a menos que exista una voluntad divina subyaciéndolos. Esta voluntad divina (Gnosis) no puede ser comprendida por el ser humano, solamente aceptada por la fe.

En este sentido, la inundación se vuelve un actor significante en las transformaciones epistemológicas e históricas propuestas por el relato y, sin embargo, la inundación es el único actor que resiste una caracterización como actor. Quizás esto resulta de la dificultad de caracterizar las inundaciones en general, dado que realmente no hay nada esencial en ellas. Una inundación es siempre una inundación de otra cosa, otra sustancia, típicamente agua. En otras palabras, una inundación jamás es esencialmente una inundación, sino solamente la instancia de otra sustancia esencial haciéndose "inundativa". Se puede considerar como una cualidad estética obtenida a través de la transformación de esta otra sustancia esencial.

Vista como objeto estético, la inundación exhibe dos dimensiones temporales. La primera es su futuridad: "Habrá inundación". Esto es, primero hay que ser una sustancia esencial - digamos, para los propósitos argumentativos, el agua compuesta por dos átomos de hidrógeno enlazados a un átomo de oxígeno- para que después emerja una inundación como atributo estético de esta sustancia. Primero hay agua y, aunque no se puede predecir cuándo exactamente, sabemos que esta agua inundará en algún punto en el futuro. La segunda dimensión, a diferencia de la primera, es su presencia: el agua no se hará inundativa hasta que sea sabido como una inundación. Es menester notar, registrar o reconocer conscientemente el tiempo presente de la inundación, que es simplemente decir que una inundación no es inundativa hasta que golpea contra otro cuerpo, sea un cuerpo geológico o arquitectónico o humano. En 
términos de su temporalidad, inundar implica gnosis, conocimiento de los dos tiempos gramaticales o poéticos de la inundación: el futuro (habrá inundación) y el futuro perfecto (habrá habido inundación).

Estos aspectos estéticos y poéticos de la inundación son determinados por la ley natural, dados ciertos parámetros de masa, volumen, inercia, fuerza gravitacional, etc. La única fuerza suficientemente poderosa para decidir la excepción a estas leyes naturales tendría que ser, por definición, sobrenatural. Citemos, por ejemplo, el Génesis 9, 11: "Yo estableceré mi alianza con ustedes: los mortales ya no volverán a ser exterminados por las aguas del Diluvio, ni habrá otro diluvio para devastar la tierra" (Biblia de ferusalén). Pero, por supuesto, este acto divino de excepción soberana es precisamente el mismo que está invalidado en la primera oración de El Matadero: "A pesar de que la mía es historia, no la empezaré por el arca de Noé y la genealogía de sus ascendientes, como acostumbraban hacerlo los antiguos historiadores españoles de América, que deben ser nuestros prototipos. Tengo muchas razones para no seguir ese ejemplo, las que callo por no ser difuso" (123). Al rechazar el Génesis, Echeverría implícitamente rechaza el orden colonial español también, la fuerza opresora que una historiografía colonial ejercía sobre las nuevas repúblicas independientes. Al mismo tiempo, sin embargo, en el proceso de rechazar el colonialismo, puede ser que Echeverría también haya liquidado las bases jurídicas del establecimiento de un contrato social nuevo.

El mito del Diluvio tiene importancia desde una perspectiva jurídica pues establece el derecho divino de los reyes. Después de que Noé preparó un sacrificio animal al desembarcar del Arca, Dios le comunica que delega en él la soberanía sobre los asuntos de los hombres y también la autoridad de re-delegar esta soberanía a sus hijos. Al des-autorizar el mito, Echeverría intenta negar el derecho divino a la monarquía española de basar su soberanía en un origen canónico. Aparte de justificar la soberanía de ciertos linajes, el mito del Diluvio además cumple la función de dividir el mundo entre la ley natural y la ley positiva. Antes de este, solo hay Ley indiferenciada: Dios deja vivir o deja morir. Después del Diluvio, c'est moi, un rey humano: Dios y Noé entran en un acuerdo contractual. Los términos del contrato son los siguientes: 1) Dios se ha cansado de reinar sobre los asuntos de los hombres, quienes siempre lo decepcionan; 2) Por eso Dios asigna la soberanía sobre el terreno social a Noé y sus hijos; 3) Dios se reserva la soberanía sobre el reino de la naturaleza; y 4) Dios sella el contrato con un arcoíris. Podríamos llamar a este Alianza el "Ur-Contrato Social": el contrato social que origina y garantiza cualquier contrato social posterior.

El "Ur" del Ur-Contrato Social sirve no solamente como origen históricotemporal, sino como origen geográfico y social. Garantiza un terreno social para 
la soberanía. Hasta ahora solo hemos considerado la inundación en El Matadero en su dimensión temporal, como tiempos del futuro y del futuro perfecto, de lo que se conocerá y lo que se habrá conocido. Pero el aspecto principal de la inundación no es el gnosis, sino obviamente su physis, su carácter físico devastador. Físicamente la inundación se define como un desplazamiento masivo: la repentina des-localización y re-localización de una sustancia de un lugar a otro lugar. Típicamente se presupone, además, que su fuerza física es exclusivamente natural. La inundación causa disturbios sociales, políticos y económicos en su secuela, pero no suele ser considerada como un ente social o político en sí mismo. Eso es así porque el Ur-Contrato Social nos otorga la base conceptual para diferenciar la ley natural de la ley positiva, siempre después-del-hecho del primer gran Diluvio. Pero, ¿qué pasaría si el mismo Ur-Contrato Social fuera invalidado o liquidado?

Si la ley natural y la ley positiva cesaran de distinguirse, entonces no sería tan significativo que la inundación hubiera sido conocida por algún sujeto-por-venir racional. Es decir, si no existiera más la barrera entre lo natural y lo humano, la inundación no dependería más de un sujeto-que-supiera transferir su energía de la naturaleza a la esfera socio-política. Al entrar en el centro cívico, no habría prohibición contra la inundación para entrar en la vida política. Al contrario, la inundación estaría en todo su derecho de convertirse en un actor político que conociera por sí mismo los cuerpos contra los cuales choca. Eso es precisamente lo que sucede en El Matadero, a pesar del hecho de que el autor/narrador de la historia aparentemente no se da cuenta de lo que ha hecho. No es que la inundación sucedió; no es simplemente que el agua sube y baja. Una vez que sucede, la inundación sigue trans-actuando contra los cuerpos humanos o animales de Buenos Aires, re-formándolos estéticamente en su propia imagen. Es una negociación política catastrófica, por supuesto, pero es política de cualquier manera.

De hecho, la única lógica causal que subyace a todos los eventos narrados en la historia es la ley de la inundación. Entonces, se podría re-narrar la historia desde una perspectiva diluvial: a primera vista, la inundación es una inundación de agua, que desplaza la rutina normal de la ciudad e induce a pena y malestar físico a los seres humanos que viven allí. La primera interrupción de agua lleva a una inundación secundaria de recriminaciones políticas emanadas de las iglesias, y también desplaza el equilibrio económico normal de oferta y demanda, especialmente con respecto al precio de los alimentos esenciales. El desequilibrio económico conduce a alteraciones repentinas en la dieta y la nutrición, de las cuales emana una inundación de pedos en todos los lugares de la ciudad, que aunque hayan sido malinterpretados por los poderes-que-sean, de todos modos provocan el desplazamiento de la ley eclesiástica gobernando prohibiciones alimentarias. Por consiguiente, una manada de cuarenta y 
nueve novillos más un toro es llevada al matadero, y sus entrañas inundan esos terrenos. Mujeres hambrientas tratan de robar el detrito animal y, consecuentemente, son bombardeadas por un torrente de sangre, barro y vísceras, que lleva a todos los demás hambrientos a derramar una tormenta de desechos. Desafortunadamente, el toro es el último en entrar en el corral para ser ejecutado, y por casual que resulte su apariencia, él hace exactamente lo que está en la naturaleza de un toro en esta situación: se hace un toro bravío, rompe los lazos que lo suprimen, supera los bordes de su cautiverio y se derrama sobre los límites territoriales del matadero. Al tratar de controlarlo, sus captores gastan una energía incontrolada, desplazan la cabeza de un muchacho cuya sangre se derrama de su cuello decapitado. Antes de que se sepa lo que ha pasado, el toro ha inundado las calles de Buenos Aires, seguido por la muchedumbre que asimismo las inunda. Desplazan a un inglés. Después de dominar y matar al toro, sucede que pasa un unitario, un pez fuera del agua, des-localizado. La energía estática de la muchedumbre se desplaza en el sistema nervioso central del unitario en forma de terror y pánico, hasta que su sangre y vísceras se derraman explosivamente de su cuerpo sobre la casilla del matadero.

En su aspecto físico (physis), la dimensión estética de la inundación es unitaria y está únicamente presente: la inundación es... des-plazamiento. La historia de Echeverría sucede dentro de una unidad del tiempo y espacio - un plazo finito y un lugar fijo, desde los cuales el centro de la capital queda invisible. No hay plazas en el Buenos Aires de El Matadero. O, mejor, la "plaza" en este mundo diegético es otro nombre para el "sin lugar", un marcador de un lugar que puede existir al otro lado del horizonte del escenario de la acción, pero que no se ve y no se habita. De esta manera, Echeverría retrata a Buenos Aires como una polis sin agora. Es un centro político sin una plaza central para centrar su desarrollo político. Por lo tanto, el único contrato social disponible al pueblo representado es el que garantiza la barbarie y el uso gratuito de la fuerza física. Aquí la physis siempre precede al gnosis; o, mejor dicho, no hay tiempo para concebir lo que pasa, porque la physis siempre precede más al physis. Un hecho político que parece tan verdadero en 183 ... como en $197 \ldots$ o 201...:

En aquel tiempo, los carniceros degolladores del Matadero eran los apóstoles que propagaban a verga y puñal la federación rosina, y no es difícil imaginarse qué federación saldría de sus cabezas y cuchillas. Llamaban ellos salvaje unitario, conforme a la jerga inventada por el Restaurador, patrón de la cofradía, a todo el que no era degollador, carnicero, ni salvaje, ni ladrón; a todo hombre decente y de corazón bien puesto, a todo patriota amigo de las luces y de la libertad; y por el suceso anterior puede verse a las claras que el foco de la federación estaba en el matadero. (139) 
El foco central de la República está ya siempre des-centrado. No hay plaza, solo hay des-plaza-miento.

La Ley de la Inundación, su contrato social liquidado: ¡Gobernar es desplazar!

\section{Obras citadas}

Agamben, Giorgio. State of Exception. Trad. Kevin Attell. Chicago: The University of Chicago Press, 2005 [2003]. Impreso.

Alberdi,Juan Bautista. Bases y puntos de partida para la organización política de la República Argentina. Buenos Aires: La Cultura Argentina, 1915 [1852]. Impreso. Altamirano, Carlos, y Beatriz Sarlo. Prólogo. Echeverría, Esteban. Obras escogidas. Eds. Carlos Altamirano y Beatriz Sarlo. Caracas: Biblioteca Ayacucho, 1991. ix-li. Impreso.

Bataille, George. The Accursed Share. Trad. Robert Hurley. Vols. II-III. Nueva York: Zone Books, 1991 [1967]. Impreso.

Biblia de ferusalén. 1975. Web. 30 abril 2015.

Echeverría, Esteban. Obras escogidas. Eds. Carlos Altamirano y Beatriz Sarlo. Caracas: Biblioteca Ayacucho, 1991. Impreso.

Kohan, Martín. "Las fronteras de la muerte". Las brújulas del extraviado: para una lectura integral de Esteban Echeverría. Eds. Martín Kohan y Alejandra Laera. Rosario: Beatriz Viterbo Editora, 2006. 171-204. Impreso.

Moreiras, Alberto. Linea de sombra: El no sujeto de lo político. Santiago de Chile: Palinodia, 2006. Impreso.

Ramos, Julio. Desencuentros de la modernidad en América Latina: literatura y política en el siglo XIX. México: Fondo de Cultura Económica, 1989. Impreso.

Rodríguez, Fermín. "Un desierto de ideas". Las brújulas del extraviado: para una lectura integral de Esteban Echeverría. Eds. Martín Kohan y Alejandra Laera. Rosario: Beatriz Viterbo Editora, 2006. 149-170. Impreso.

Schmitt, Carl. Political Theology: Four Chapters on the Concept of Sovereignty. Trad. George Schwab. Cambridge, MA: The MIT Press, 1985 [1922]. Impreso.

Sorbille, Martin. "Rosas qua objet petit a: la omnipotencia de su voz-superyó y mirada en 'El matadero' de Esteban Echeverría”. Chasqui: Revista de literatura latinoamericana 38.2 (2009): 94-112. Impreso.

Wasserman, Fabio. "Política, escritura y nación (la primera lectura en el Salón Literario y El Dogma Socialista)". Las brújulas del extraviado: para una lectura integral de Esteban Echeverría. Eds. Martín Kohan y Alejandra Laera. Rosario: Beatriz Viterbo Editora, 2006. 205-224. Impreso.

Žižek, Slavoj. The Parallax View. Cambridge, MA: The MIT Press, 2006. Impreso. 